\title{
Cocaine Dose and Self-Administration History, but Not Initial Cocaine Locomotor Responsiveness, Affects Sensitization to the Motivational Effects of Cocaine in Rats
}

\author{
Bruce H. Mandt, Emily Gomez, Nickie L. Johnston, Nancy R. Zahniser, \\ and Richard M. Allen
}

Department of Psychology, University of Colorado Denver, Denver, Colorado (B.H.M., E.G., N.L.J., R.M.A.); and Department of Pharmacology and Neuroscience Program, University of Colorado Anschutz Medical Campus, Aurora, Colorado (N.R.Z.)

Received March 7, 2012; accepted April 18, 2012

\begin{abstract}
Cocaine addiction is a significant and complex disease. Part of this complexity is caused by the variability of the drug experience early in drug use (initial responsiveness, amount of use, etc.). In rats, individual differences in initial cocaine responsiveness and cocaine self-administration history both predict the development of cocaine sensitization, a putative mechanism contributing to the development of cocaine addiction. Here, we sought to determine the role of these factors and cocaine dose on the development of sensitization to cocaine's motivational effects during the earliest stages of self-administration. Rats were classified as either low or high cocaine responders (LCRs or HCRs, respectively) based on acute cocaine-induced locomotor activity $(10 \mathrm{mg} / \mathrm{kg}$ i.p.) before learning to self-administer cocaine $(0.6 \mathrm{mg} / \mathrm{kg} /$ infusion i.v.) under a fixed ratio 1 (FR1)
\end{abstract}

schedule of reinforcement. After acquisition, rats self-administered cocaine $(0.6$ or $1.2 \mathrm{mg} / \mathrm{kg} /$ infusion) under a progressive ratio $(\mathrm{PR})$ schedule of reinforcement either immediately or after an additional five FR1 sessions ( 0.6 or $1.2 \mathrm{mg} / \mathrm{kg} /$ infusion). No $\mathrm{LCR} / \mathrm{HCR}$ differences in sensitization were observed. However, regardless of LCR/HCR classification, exposure to the higher dose of cocaine produced sensitization to cocaine's motivational effects on the PR schedule (i.e., increased break points) and an escalation of consumption on the FR schedule. Thus, our results reveal a novel model for studying escalation and sensitization very early after acquisition and suggest that sensitization may be important in the earliest stages of the cocaine addiction process.

\section{Introduction}

Cocaine addiction remains a significant public health issue. Recent statistics from the United States indicate that as of 201037.2 million people aged 12 and over had tried cocaine at least once in their lifetimes, with approximately 1.5 million current cocaine users (Substance Abuse and Mental Health Services Administration, 2011). These statistics are particularly troubling considering an estimated 10 to $15 \%$ of all initial intranasal cocaine users progress to addiction (Gawin, 1991). For a subset of these individuals, the transition from recreational use to addiction occurs very rapidly and is associated with routes of administration that result in

This work was supported by the National Institutes of Health National Institute on Drug Abuse [Grants R01 DA004216, K05 DA015050] and an American Society for Pharmacology and Experimental Therapeutics Summer Undergraduate Research Fellowship (to E.G.).

Article, publication date, and citation information can be found at http://jpet.aspetjournals.org.

http://dx.doi.org/10.1124/jpet.112.194092 more rapid and higher brain cocaine levels (Wagner and Anthony, 2002; O'Brien and Anthony, 2005). Furthermore, individual differences in the initial subjective effects of cocaine have been found to correlate with long-term use and dependence (Lambert et al., 2006). Thus, understanding factors that contribute to the rapid development of this disease in susceptible individuals remains an important and significant challenge.

Addiction has been defined as "a chronic disorder characterized by the compulsive use of a substance resulting in physical, psychological, or social harm to the user and continued use despite that harm" (Rinaldi et al., 1988). Because of the complex etiology of addiction, animal models tend to focus on one aspect of the human condition (but see DerocheGamonet et al., 2004). For example, the long access model of cocaine self-administration and extinction/reinstatement paradigms model escalation in cocaine consumption and "relapse" to cocaine use, respectively (Ahmed and Koob, 1998; Shaham et al., 2003), but do so after stable patterns of

ABBREVIATIONS: PR, progressive ratio; LCR, low cocaine responder; HCR, high cocaine responder; FR1, fixed ratio 1; RMANOVA, repeatedmeasures analysis of variance; inf, infusion. 
self-administration have been established. We are interested in factors that occur earlier in the drug-taking process, and we have recently established a method for measuring cocaine consumption during the earliest stages of self-administration. This method defines acquisition based on intake criteria and then measures each subject's postacquisition intake relative to the day of acquisition (day $x$ ), allowing for experimental manipulations after very limited initial cocaine exposure (Mandt et al., 2012).

One factor postulated to be important for the transition from recreational drug use to addiction is sensitization (Robinson and Berridge, 1993, 2001). In animals, sensitization to the locomotor-stimulating effects of drugs such as cocaine has been demonstrated for years (Post, 1980; Zahniser et al., 1988; Kalivas and Duffy, 1993); however, whether sensitization is seen in humans and nonhuman primates is an area of active debate (Bradberry, 2007). One possibility for this discrepancy is that sensitization in humans may occur while addiction is developing, before the individual has entered treatment and subsequent clinical studies. Likewise, sensitization may also be more difficult to demonstrate during contingent (i.e., drug self-administration) than noncontingent (i.e., experimenter administered) cocaine exposure, because it occurs very early in the drug-taking process while animals are being trained on the operant. Nonetheless, sensitization during paradigms of cocaine self-administration has been demonstrated. For example, Roberts and colleagues have reported environmental conditions that result in sensitization to the reinforcing effects of cocaine measured with a progressive ratio (PR) schedule of reinforcement (Morgan and Roberts, 2004; Liu et al., 2005; Morgan et al., 2006).

Over the past 10 years, we have worked with a model of individual differences in rats that distinguishes animals based on the magnitude of their acute locomotor response to a single cocaine injection (10 mg/kg i.p.; Sabeti et al., 2002). One of the most consistent behavioral findings has been that rats with lower, but not higher, initial responsiveness to cocaine [low cocaine responders (LCRs), but not high cocaine responders (HCRs)] more readily develop cocaine-induced locomotor sensitization after repeated noncontingent cocaine (10 mg/kg i.p.) (Sabeti et al., 2003; Allen et al., 2007; Mandt et al., 2008, 2009; Nelson et al., 2009). It is noteworthy that the LCR/HCR difference in cocaine-induced locomotor sensitization was not found to predict acquisition of low-dose cocaine self-administration (Mandt et al., 2008). However, whether LCRs and HCRs differ in the development of other forms of sensitization (e.g., during contingent cocaine selfadministration) remains unknown.

Thus, the present study sought to investigate the role of self-administration history and initial cocaine responsiveness on the development of sensitization to the motivational effects of cocaine. Specifically, we used our new method of acquisition analysis combined with PR schedules of cocaine reinforcement to determine whether: 1) we could establish conditions that reveal sensitization to the motivational effects of contingent cocaine administration and 2) LCRs and HCRs differ in the development of this form of sensitization.

\section{Materials and Methods}

Animals. Four groups of outbred male Sprague-Dawley rats ( $n=$ 70 ; group $\mathrm{A}, n=16$; group $\mathrm{B}, n=14$; group $\mathrm{C}, n=20$; group $\mathrm{D}, n=$
20 ), weighing between 225 and $250 \mathrm{~g}$ ( $\sim 8$ weeks of age), were purchased from Charles River Breeding Laboratories (Portage, MI) and used in this study. All rats were housed individually with ad libitum access to food and water in an animal care facility at the University of Colorado, Denver, CO. To remain consistent with all previous LCR/HCR studies, rats were housed on a 12-h light/dark cycle (lights on at 6:00 $\mathrm{AM}$ ), and all testing was conducted during the light cycle. All animal care and use procedures were in strict accordance with the National Institutes of Health Guide for the Care and Use of Laboratory Animals (Institute of Laboratory Animal Resources, 1996) and approved by the University of Colorado Denver Institutional Animal Care and Use Committee.

Catheter Construction and Placement. Intravenous catheters were constructed in the laboratory and surgically implanted into the right jugular vein under ketamine (100 mg/kg i.m.) and xylazine (10 $\mathrm{mg} / \mathrm{kg}$ i.m.) anesthesia by using established procedures (Thomsen and Caine, 2005). Rats received acetaminophen as an analgesic in their drinking water $(20 \mathrm{mg} / \mathrm{ml})$ for $48 \mathrm{~h}$ before and after surgery. Rats recovered from surgery for at least 1 week before self-administration training began. Catheters were flushed with $0.3 \mathrm{ml}$ of bacteriostatic $0.9 \%$ sodium chloride containing heparin $(30 \mathrm{U} / \mathrm{ml})$ both before and after each self-administration session. Sodium thiopental (20 $\mathrm{mg} / \mathrm{kg}$ i.v.) was administered at the conclusion of the experiment to verify catheter patency.

Locomotor Activity. Locomotor activity testing was conducted as described previously (Sabeti et al., 2002; Mandt and Zahniser, 2010) and consisted of a single cocaine exposure 48 to $72 \mathrm{~h}$ before self-administration training. In brief, rats were taken to the behavioral testing room in their home cages and allowed to habituate for 45 to $60 \mathrm{~min}$. At the start of the behavioral recording session, rats were placed in open field activity chambers consisting of Plexiglas boxes $(43.2 \times 43.2 \mathrm{~cm})$ fitted with a photobeam frame (16 beams per dimension; MED Associates, St. Albans, VT). After acclimation to the novel environment for $90 \mathrm{~min}$, rats were injected with cocaine (10 $\mathrm{mg} / \mathrm{kg}$ i.p.) and returned to the chamber for $30 \mathrm{~min}$. Locomotor activity was quantified by using the automated consecutive horizontal photobeam interruptions converted to distance traveled (centimeters) per 10-min bin. The sum of distance traveled over the $30 \mathrm{~min}$ postcocaine was used to determine the median split for all rats within each of the four groups, which was then used to classify rats as either LCRs or HCRs.

Self-Administration Training. Rats self-administered cocaine during the light cycle in 16 Plexiglas and metal operant conditioning chambers $(29 \times 24 \times 21 \mathrm{~cm}$; MED Associates $)$ that were housed within sound-attenuating cabinets. The chambers had two retractable levers on the front wall with stimulus lights positioned $6 \mathrm{~cm}$ above each lever. A tone presentation speaker (Sonalert Tone Generator, $2900 \mathrm{~Hz}$; MED Associates) and a white noise speaker (90 dB) were mounted $12 \mathrm{~cm}$ above the floor on the wall opposite the levers. A house light (100 $\mathrm{mA}$ ) was mounted $6 \mathrm{~cm}$ above the tone speaker, and a computer-controlled syringe pump delivered cocaine infusions. All behavioral events were monitored and controlled by a personal computer using MED-PC for Windows software (MED Associates).

All self-administration sessions began with the extension of the retractable levers, white-noise activation, and illumination of the stimulus light on the right side of the chamber. For fixed ratio 1 (FR1) sessions, $1 \mathrm{~s}$ after session initiation, a cocaine priming infusion was delivered $(0.6$ or $1.2 \mathrm{mg} / \mathrm{kg} /$ infusion in a volume of 0.2 $\mathrm{ml}$ over $5-7 \mathrm{~s}$, based on the weight of the rat). During this priming infusion and all subsequent self-administered infusions, the stimulus light over the active lever was turned off, and a tone-house light stimulus complex was activated for $15 \mathrm{~s}$ coinciding with a "timeout" period.

Acquisition of cocaine self-administration was measured in 2-h sessions, and testing was conducted 5 days a week. Responses on the right lever were reinforced with a cocaine infusion $(0.6 \mathrm{mg} / \mathrm{kg}) \mathrm{ac}$ cording to a FR1 schedule of reinforcement. All groups (A-D) acquired cocaine self-administration with this training dose. Re- 
sponses emitted on the right lever during cocaine infusion and stimulus complex (i.e., timeout) were not reinforced and were recorded separately from reinforced responses. Responses on the left lever were recorded but had no programmed consequence. Acquisition in these experiments was defined as the first of three consecutive sessions during which a rat consumed at least $4 \mathrm{mg} / \mathrm{kg}$ cocaine (Mandt et al., 2012). In our work, rats that meet these criteria continue to reliably self-administer cocaine; and these criteria are similar to intake-based acquisition criterion used by other laboratories (Carroll and Lac, 1997; Mantsch et al., 2001).

After acquisition, rats that met criterion were advanced to PR testing either immediately (groups A and B) or after an additional five FR1 sessions (groups C and D). Similar to FR testing, PR testing was conducted 5 days a week, and responding was reinforced with either $1.2 \mathrm{mg} / \mathrm{kg} / \mathrm{infusion}$ cocaine (groups A and C) or $0.6 \mathrm{mg} / \mathrm{kg} /$ infusion cocaine (groups B and D). PR sessions were $5 \mathrm{~h}$ in duration, and the response requirement increased progressively according to the following schedule: $1,2,4,6,9,12,15,20,25,32,40,50,62,77$, $95,118,145,178,219,268,328,402,492,603$, and 737 for cocaine infusions 1 to 25, respectively (Richardson and Roberts, 1996). Break point was defined as the last response ratio completed before $1 \mathrm{~h}$ without earned reinforcement or the end of $5 \mathrm{~h}$. As with the FR sessions, left lever responses were recorded but had no programmed consequences. The details of experimental conditions for each group are shown in Table 1.

Exclusions and Exceptions. In total, 20 of the 70 rats used in this study were excluded from final PR analysis. One rat in group $\mathrm{A}$, two rats in group $\mathrm{B}$, four rats in group $\mathrm{C}$, and six rats in group $\mathrm{D}$ did not acquire cocaine self-administration. An additional three rats (one in group B and two in group D) had catheter patency failure before the end of the acquisition phase of the study. Two rats (one in group A and one in group C) had catheter patency failure after acquisition, but before the end of PR testing, and as such, these rats were included in acquisition, but not $\mathrm{PR}$ analysis. One rat in group $\mathrm{C}$ underwent locomotor classification, but was not advanced to self-administration testing because of health concerns. Finally, one rat in group D was advanced prematurely to PR testing and thus was not included in group D intake or PR analysis.

Data Analysis. All statistical analyses were conducted by using PASW Statistics, version 18.0 (IBM, White Plains, NY). For acquisition analysis, cocaine intake on the session before acquisition and three postacquisition sessions was analyzed with three-way repeatedmeasures analysis of variance (RMANOVA). Classification (LCR or HCR), group (A and B or C and D), and session (within-subjects variable) were treated as independent variables, and intake was treated as the dependent measure. Postacquisition intake analysis in groups $\mathrm{C}$ and D was analyzed with three-way RMANOVA. Classification, dose ( 0.6 or $1.2 \mathrm{mg} / \mathrm{kg} /$ infusion), and session were treated as independent variables, and cocaine intake was treated as the dependent measure. The PR experiments were analyzed with three-way RMANOVA. Classification, dose (0.6 or $1.2 \mathrm{mg} / \mathrm{kg} / \mathrm{infusion})$, and session were treated as independent variables, and break pointassociated infusions were treated as the dependent measure. When main or interaction effects were revealed, independent samples $t$ tests or one-way RMANOVA were used for post hoc analyses. When the assumption of sphericity was violated for a particular repeated- measures analysis, as revealed by Mauchly's test statistic, tests of significance were based on the more conservative Huynh-Feldt corrected degrees of freedom. Superscript a $\left({ }^{a}\right)$ indicates Huynh-Feldt corrected values throughout the text. Between-groups analysis of break point-associated infusions on the first PR session were analyzed with independent samples $t$ tests (group A versus C or group B versus D).

Drugs. The National Institute on Drug Abuse (Bethesda, MD) generously provided the (-)cocaine hydrochloride used in these studies. For intraperitoneal injections, cocaine was dissolved in sterile saline $(0.9 \%$ sodium chloride) at a concentration of 10 $\mathrm{mg} / \mathrm{ml}$ and administered in a volume of $1 \mathrm{ml} / \mathrm{kg}$. For intravenous infusions, cocaine was dissolved in sterile saline containing 1.7 USP units/ml heparin. To check catheter patency, sodium thiopental (Sigma-Aldrich, St. Louis, MO) was dissolved in saline and administered intravenously at $20 \mathrm{mg} / \mathrm{kg}$. Drug weights refer to the salt.

\section{Results}

Groups A and B: Cocaine Self-Administration on a FR1 Schedule of Reinforcement. Groups A and B were given 20 sessions to acquire cocaine self-administration $(0.6$ $\mathrm{mg} / \mathrm{kg} /$ infusion) by using a FR1 schedule of reinforcement. Overall, 15/16 rats in group A and 11/13 rats in group B met criteria within this timeframe with average times to acquisition of $6.5 \pm 1.3$ and $6.9 \pm 1.2$ days, respectively. Cocaine intake over the two sessions before acquisition and three acquisition sessions are shown in Fig. 1A. It should be noted that three rats in group A met criterion starting on the first day of the experiment and, consequently, do not have $x-2$ and $x-1$ values. Thus, $n$ values are decreased for those time points in both the data analysis and Fig. 1, A and B. Analysis of cocaine intake over the session before acquisition $(x-1)$ and three acquisition sessions ( $x$ to $x+2)$ with three-way RMANOVA revealed a significant effect of $\operatorname{session}\left(F_{3,66}=\right.$ $70.7 ; p<0.001$ ), but no other significant effects or interactions. Compared with sessions $x-1$ and $x$, rats in both groups consumed significantly more cocaine on sessions $x+$ 1 and $x+2$, but intake was not significantly different between the groups.

Active and inactive lever responding in groups A and B over the two sessions before acquisition and three acquisition sessions are shown in Fig. 1B. Although the ratio of active to inactive lever responding was not part of the acquisition criterion, rats in both groups displayed clear lever discrimination upon meeting our intake criterion. By the third acquisition session, rats in groups A and B displayed a more than 10:1 ratio of active to inactive lever responding (Fig. 1B).

Groups A and B: Postacquisition Cocaine Self-Administration on a PR Schedule of Reinforcement. After acquisition, rats were immediately advanced to PR testing reinforced by either a higher dose ( $1.2 \mathrm{mg} / \mathrm{kg} /$ infusion; group A)

TABLE 1

Experimental groups

\begin{tabular}{cccc}
\hline Group & Acquisition Sessions and Cocaine Doses & Postacquisition Sessions and Cocaine Doses & PR Sessions and Cocaine Doses \\
\hline A, $n=15^{*}$ & $3 \times$ FR1, 0.6 mg/kg/inf & & $10 \times \mathrm{PR}, 1.2 \mathrm{mg} / \mathrm{kg} / \mathrm{inf}$ \\
$\mathrm{B}, n=11$ & $3 \times \mathrm{FR} 1,0.6 \mathrm{mg} / \mathrm{kg} / \mathrm{inf}$ & & $10 \times \mathrm{PR}, 0.6 \mathrm{mg} / \mathrm{kg} / \mathrm{inf}$ \\
$\mathrm{C}, n=15^{*}$ & $3 \times \mathrm{FR} 1,0.6 \mathrm{mg} / \mathrm{kg} / \mathrm{inf}$ & $5 \times \mathrm{FR} 1,1.2 \mathrm{mg} / \mathrm{kg} / \mathrm{inf}$ & $10 \times \mathrm{PR}, 1.2 \mathrm{mg} / \mathrm{kg} / \mathrm{inf}$ \\
$\mathrm{D}, n=12$ & $3 \times \mathrm{FR} 1,0.6 \mathrm{mg} / \mathrm{kg} / \mathrm{inf}$ & $5 \times \mathrm{FR} 1,0.6 \mathrm{mg} / \mathrm{kg} / \mathrm{inf}$ & $10 \times \mathrm{PR}, 0.6 \mathrm{mg} / \mathrm{kg} / \mathrm{inf}$ \\
\hline
\end{tabular}

* One rat in group A and one rat in group C were excluded after the acquisition phase and, as such, $n$ values for PR testing were 14 for both groups A and C (see $M a t e r i a l s$ and Methods: Exclusions and Exceptions. 
A

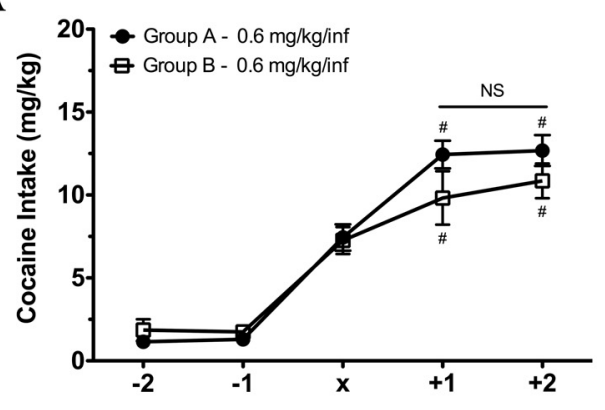

B

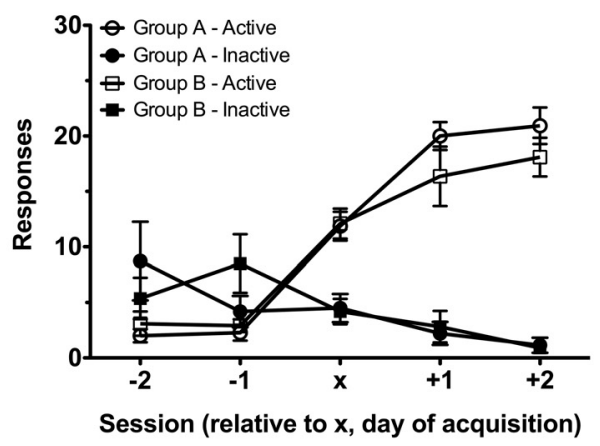

C

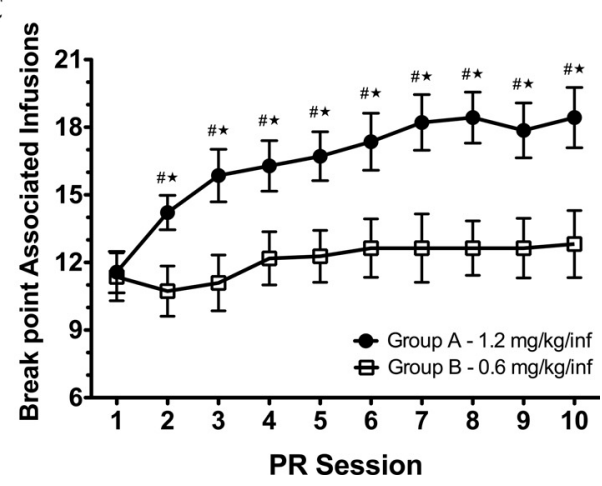

Fig. 1. Cocaine self-administration in groups A and B, regardless of LCR/HCR classification, which were advanced to PR testing immediately after acquisition (see Table 1). A, cocaine intake ( $0.6 \mathrm{mg} / \mathrm{kg} / \mathrm{inf})$ is shown for the two sessions before acquisition and three acquisition sessions in groups $\mathrm{A}(n=15)$ and $\mathrm{B}(n=11) . x$ represents the day of acquisition. \#, $p<0.05$ each session versus session $x-1$ and $x$. NS, not significant. B, active and inactive lever responding for the same acquisition sessions as in A. C, break point-associated infusions over the $10 \mathrm{PR}$ sessions in groups A (1.2 mg/kg/inf; $n=14)$ and B $(0.6 \mathrm{mg} / \mathrm{kg} / \mathrm{inf} ; n=11)$. $*, p<0.05$ group A versus group B. \#, $p<0.05$ each session versus session $x-3$. Data are mean values \pm S.E.M. It should be noted that $n$ values in $\mathrm{A}$ and B represent data for sessions $x$ to $x+3$, because three animals in group A do not have data from sessions before $x$ (i.e., acquisition occurred on the first session), thus $n$ values are lower for those data points.

or the training dose $(0.6 \mathrm{mg} / \mathrm{kg} /$ infusion; group B) of cocaine. Analysis with three-way RMANOVA revealed a significant effect of session $\left({ }^{\mathrm{a}} F_{9,189}=8.5 ; p<0.001\right)$, dose $\left(F_{1,21}=6.9 ; p=\right.$ $0.015)$, and a session $\times$ dose interaction $\left({ }^{\mathrm{a}} F_{9,189}=2.4 ; p=\right.$ 0.048), but no other significant effects or interactions.

Consistent with previous reports (Liu et al., 2005), break points did not differ on the first PR session despite the different cocaine doses (Fig. 1C). However, break points in group A (1.2 mg/kg/infusion) increased significantly over the next nine sessions, whereas break points in group B $(0.6$ $\mathrm{mg} / \mathrm{kg} /$ infusion) did not change. Separate post hoc analyses with one-way RMANOVA revealed a significant effect of ses- sion for group A $\left(F_{9,117}=11.6 ; p<0.001\right)$, but not for group B. Compared with the first PR session, break points in group A were significantly increased on sessions 2 to 10 . There were additional significant differences between other sessions in group A (e.g., session 2 versus session 10) that are not indicated. In addition, independent samples $t$ tests revealed that, although initial break points in groups A and B were not different, break points in group A were significantly increased on each of the next nine sessions (Fig. 1C). A summary of selfadministration parameters for LCRs and HCRs in groups A and B, which did not differ, is presented in Table 2.

Groups C and D: Postacquisition Cocaine Self-Administration on a FR1 Schedule and Subsequent Performance on a PR Schedule of Reinforcement. The increase in break points seen in group A, but not group B, was suggestive of a dose-related sensitization to the motivational effects of cocaine. However, it was possible that a switch in cocaine dose and reinforcement schedule $(0.6 \mathrm{mg} / \mathrm{kg} / \mathrm{infusion}$ on a FR1 to $1.2 \mathrm{mg} / \mathrm{kg} /$ infusion on a PR) produced competing behaviors in group A, resulting in the lower initial break points. Thus, to investigate this possibility rats in groups $\mathrm{C}$ and $\mathrm{D}$ were given five additional FR1 sessions reinforced by either 1.2 or $0.6 \mathrm{mg} / \mathrm{kg} / \mathrm{infusion}$ cocaine, respectively, before advancement to PR testing at those same doses.

Similar to groups A and B, groups C and D were given 20 sessions to acquire cocaine self-administration $(0.6 \mathrm{mg} / \mathrm{kg} /$ infusion) according to a FR1 schedule of reinforcement. Overall, 15/19 rats in group $\mathrm{C}$ and 12/17 rats in group D met criteria in this timeframe with average days to acquisition of $7.1 \pm 0.7$ and $10.2 \pm 1.5$, respectively; this difference was not significant. After acquisition (i.e., after session $x+2$ ), groups $\mathrm{C}$ and D self-administered cocaine $(1.2$ or $0.6 \mathrm{mg} / \mathrm{kg} / \mathrm{infusion}$, respectively) on a FR1 schedule for five additional sessions. Cocaine intake over the two sessions before acquisition, the three acquisition sessions, and the five additional FR1 sessions are shown in Fig. 2A. Analysis of cocaine intake over the session before $(x-1)$ and three acquisition sessions $(x$ to $x+2$ ) with three-way RMANOVA revealed a significant effect of session $\left({ }^{a} F_{3,69}=24.6 ; p<0.001\right)$, but no other significant effects or interactions. Relative to session $x-1$, rats in both groups $\mathrm{C}$ and $\mathrm{D}$ consumed significantly more cocaine in sessions $x$ to $x+2$.

In contrast to the acquisition sessions, analysis of the five additional FR1 sessions revealed significant effects of session $\left(F_{4,92}=21.6 ; p<0.001\right)$, dose $\left(F_{1,23}=15.4 ; p=0.001\right)$, classification $\times \operatorname{session}\left(F_{4,92}=2.9 ; p=0.026\right)$, and dose $\times$ session $\left(F_{4,92}=5.7 ; p<0.001\right)$ interactions. Separate analysis of intake with one-way RMANOVA revealed a significant effect of session in group $\mathrm{C}\left(F_{4,56}=26.3 ; p<0.001\right)$, but not group D. Relative to the first session of $1.2 \mathrm{mg} / \mathrm{kg} / \mathrm{infusion}$ cocaine self-administration $(x+3)$, rats in group $\mathrm{C}$ consumed significantly more cocaine in sessions 3 to $5(x+5$ to $x+7$; Fig. 2A). Furthermore, pairwise comparisons revealed that whereas intake on session $x+3$ was not significantly different between groups $\mathrm{C}$ and $\mathrm{D}$, rats in group $\mathrm{C}$ consumed significantly more cocaine than rats in group $\mathrm{D}$ on each of the next four sessions (Fig. 2A). Analysis of classification on each of the five additional FR1 sessions did not reveal significant differences in intake between LCRs and HCRs at any point (Table 2).

After the five additional FR1 sessions, groups C and D were advanced to PR testing reinforced by either 1.2 or 0.6 
TABLE 2

Cocaine self-administration in rats classified as LCRs or HCRs

\begin{tabular}{|c|c|c|c|c|c|c|}
\hline \multirow{2}{*}{ Group } & \multicolumn{2}{|c|}{$\begin{array}{l}\text { Cocaine-Induced Locomotor } \\
\text { Activity }(\mathrm{cm} / 30 \mathrm{~min})\end{array}$} & \multirow{2}{*}{ Acquisition \% } & \multirow{2}{*}{$\begin{array}{c}\text { Average Intake } \\
(x \text { to } x+2, \mathrm{mg} / \mathrm{kg})\end{array}$} & \multirow{2}{*}{$\begin{array}{c}\text { Average Intake } \\
(x+3 \text { to } x+7, \mathrm{mg} / \mathrm{kg})\end{array}$} & \multirow{2}{*}{$\begin{array}{l}\text { Average Break } \\
\text { Point-Associated Infusions }\end{array}$} \\
\hline & Median & Mean & & & & \\
\hline \multicolumn{7}{|l|}{ A } \\
\hline LCR $(n=8)$ & 2382 & $1331 \pm 221$ & $88(7 / 8)$ & $10.3 \pm 1.4$ & & $15.5 \pm 1.6$ \\
\hline $\operatorname{HCR}(n=8)$ & & $4204 \pm 532$ & $100(8 / 8)$ & $11.3 \pm 1.5$ & & $17.0 \pm 1.8$ \\
\hline \multicolumn{7}{|l|}{ B } \\
\hline LCR $(n=7)$ & 2772 & $2065 \pm 175$ & $100(7 / 7)$ & $9.5 \pm 1.8$ & & $11.3 \pm 1.6$ \\
\hline $\operatorname{HCR}(n=7)$ & & $4914 \pm 749$ & $67(4 / 6)$ & $8.9 \pm 1.6$ & & $13.6 \pm 1.8$ \\
\hline \multicolumn{7}{|l|}{$\mathrm{C}$} \\
\hline LCR $(n=10)$ & 2750 & $1332 \pm 275$ & 89 (8/9) & $9.7 \pm 1.5$ & $15.4 \pm 1.4$ & $14.9 \pm 1.3$ \\
\hline \multirow{2}{*}{\multicolumn{7}{|c|}{$\mathrm{D}$}} \\
\hline & & & & & & \\
\hline LCR $(n=10)$ & 2363 & $1271 \pm 144$ & $88(7 / 8)$ & $7.4 \pm 0.8$ & $9.1 \pm 1.2$ & $10.2 \pm 0.9$ \\
\hline $\operatorname{HCR}(n=10)$ & & $4375 \pm 644$ & $56(5 / 9)$ & $10.0 \pm 1.5$ & $12.6 \pm 2.2$ & $13.0 \pm 1.1$ \\
\hline
\end{tabular}

A.

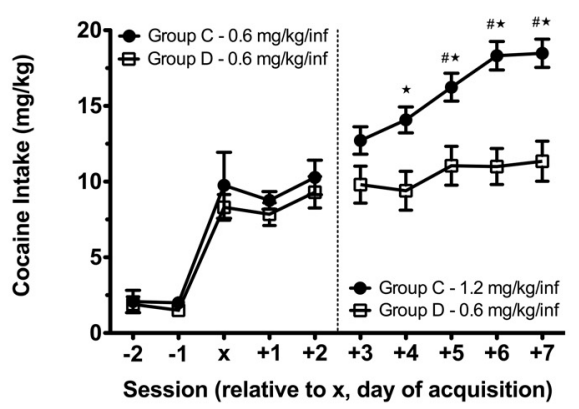

B

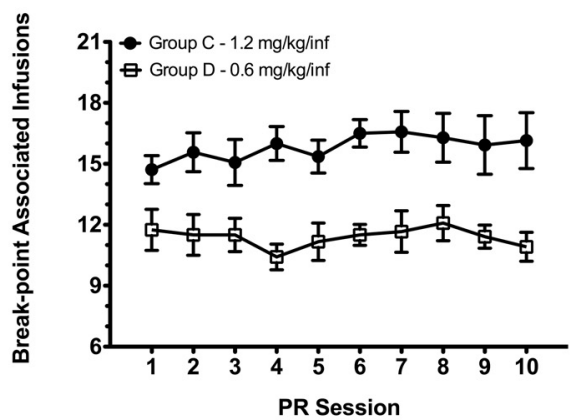

C

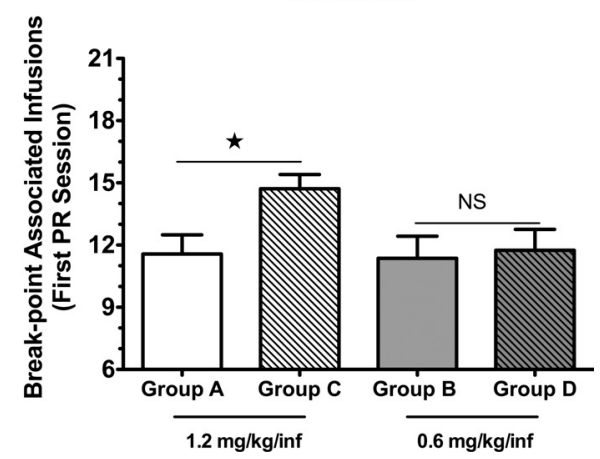

Fig. 2. Cocaine self-administration in groups $C$ and D, regardless of LCR/HCR classification, which were advanced to PR testing after an additional five postacquisition FR1 sessions (see Table 1). A, cocaine intake $(0.6 \mathrm{mg} / \mathrm{kg} / \mathrm{inf})$ is shown for the two sessions before acquisition, the three acquisition sessions in groups $\mathrm{C}(n=15)$ and $\mathrm{D}(n=12)$, and the five additional postacquisition FR1 sessions $(1.2$ or $0.6 \mathrm{mg} / \mathrm{kg} / \mathrm{inf}$, respectively). $x$ represents the day of acquisition. $\not$, $p<0.05$ group $\mathrm{C}$ versus group D. \#, $p<0.05$ each session versus session $x+3$. B, break pointassociated infusions over the $10 \mathrm{PR}$ sessions in groups $\mathrm{C}(1.2 \mathrm{mg} / \mathrm{kg} / \mathrm{inf}$; $n=14)$ and $\mathrm{D}(0.6 \mathrm{mg} / \mathrm{kg} / \mathrm{inf} ; n=12)$. C, break point-associated infusions on the first $\mathrm{PR}$ session in groups $\mathrm{A}$ to $\mathrm{D}$. $\not$,,$p<0.05$ group $\mathrm{C}$ versus group A. NS, not significant. Data are mean values \pm S.E.M. $\mathrm{mg} / \mathrm{kg} /$ infusion cocaine, respectively. Analysis of break pointassociated infusions with three-way RMANOVA revealed significant effects of classification $\left(F_{1,22}=6.5 ; p=0.018\right)$ and dose $\left(F_{1,22}=19.4 ; p<0.001\right)$, but no other significant effects or interactions (Fig. 2B). Pairwise comparison of the main effect of classification revealed that HCRs exhibited significantly greater break points than LCRs $(15.2 \pm 0.8$ versus $12.6 \pm 0.7$, respectively) and group $\mathrm{C}$ rats self-administering $1.2 \mathrm{mg} / \mathrm{kg} /$ infusion cocaine exhibited significantly greater break points than group D rats self-administering 0.6 $\mathrm{mg} / \mathrm{kg} /$ infusion cocaine $(16.1 \pm 0.7$ versus $11.6 \pm 0.7$, respectively). A summary of self-administration parameters for LCRs and HCRs in groups C and D is presented in Table 2.

Finally, to determine whether the five additional FR1 sessions altered the reinforcing effects of cocaine, break pointassociated infusions were compared either between groups $\mathrm{A}$ and $\mathrm{C}$ or groups $\mathrm{B}$ and $\mathrm{D}$ (i.e., groups with different histories on the FR schedule, but self-administering the same doses on the PR schedule). Analysis with independent samples $t$ tests revealed that break points on the first $\mathrm{PR}$ session were significantly greater in group $\mathrm{C}$ than group $\mathrm{A}(p=0.011)$, but there was no difference in break points between groups $\mathrm{B}$ and $\mathrm{D}(p=0.795$; Fig. $2 \mathrm{C})$.

\section{Discussion}

The current study had two aims. First, we sought to identify conditions that reveal sensitization to the motivational effects of cocaine. Second, we sought to determine whether individual differences in acute cocaine-induced locomotor activity (i.e., LCRs and HCRs) predict this form of sensitization. Although this study did not reveal differences in this form of sensitization between LCRs and HCRs, we did identify conditions that reveal sensitization to the motivational effects of cocaine. Similar to other reports (Liu et al., 2005; Morgan et al., 2006), cocaine dose and exposure history were important for sensitization on the PR schedule. It is noteworthy that a switch in cocaine dose also produced escalation of cocaine consumption on the FR1 schedule. Thus, this study replicates previous findings on the important role of cocaine dose and exposure history for sensitization to the effects of contingent cocaine and provides new evidence that sensitization may occur very early during the drug-taking process. 
Sensitization has been suggested to be important during the transition from recreational to compulsive cocaine use, and this idea has been argued most formally by proponents of the incentive-sensitization theory of addiction (Robinson and Berridge, 1993, 2001). In animals, sensitization to the locomotor-stimulating effects of drugs such as cocaine has been demonstrated for years and a great deal is known about its neurobiological mechanisms (Post, 1980; Zahniser et al., 1988; Kalivas and Duffy, 1993; Churchill et al., 1999; Grignaschi et al., 2004). However, it is not clear whether sensitization is seen in humans and nonhuman primates (Bradberry, 2007). One likely factor in this discrepancy is that humans actively take drugs, whereas animals passively receive drugs during locomotor sensitization paradigms. Consequently, demonstrating sensitization under paradigms of cocaine self-administration becomes extremely important for understanding the contribution of this phenomenon to complex emitted behaviors.

Roberts and colleagues have reported conditions that produce sensitization to the reinforcing effects of cocaine in rats evident by increasing break points on a PR schedule of reinforcement (Liu et al., 2005; Morgan et al., 2006). They found that a dose of $1.5 \mathrm{mg} / \mathrm{kg} /$ infusion cocaine produced the most robust increase in break points and limited initial exposure (e.g., 60-160 mg/kg total exposure before PR) was necessary to produce this effect. However, these studies used very specific conditions (animals housed in self-administration chambers with 12-h access to cocaine) and whether this type of sensitization could be produced under more widely used conditions (animals housed in separate rooms and 2-h sessions) remained unknown.

We have recently established a method for determining acquisition that allows for experimental manipulation of self-administration behavior during the earliest stages of the drug-taking process (Mandt et al., 2012). This method defines acquisition as the first of three consecutive sessions when a rat consumes $\geq 4 \mathrm{mg} / \mathrm{kg}$ cocaine during a 2 -h FR1 session and aligns intake to that session (i.e., day $x$; see Fig. 1A). Previously, we found that rats consuming 1.2 $\mathrm{mg} / \mathrm{kg} /$ infusion cocaine rapidly increased consumption from this point, whereas rats self-administering a range of lower doses exhibited more stable intake (Mandt et al., 2012). However, this new method of analysis was a product of that study and not part of the design. Thus, the present study used this method of analysis to assess sensitization to the motivational effects of cocaine after very limited initial cocaine exposure, similar to other reports (Liu et al., 2005; Morgan et al., 2006).

It is noteworthy that when rats were given limited exposure before PR testing (groups A and B), we found a robust replication of the Liu et al. (2005) study. In both that study and ours, break points did not differ on the first PR session regardless of cocaine dose. However, rats given the higher cocaine doses $(1.5 \mathrm{mg} / \mathrm{kg} / \mathrm{infusion}$ in their study or $1.2 \mathrm{mg} / \mathrm{kg} /$ infusion in ours) progressively increased break points over the next 5 to 10 sessions, whereas rats given the lower doses exhibited stable break points. It was possible that in our study the initial low break points for $1.2 \mathrm{mg} / \mathrm{kg} / \mathrm{infusion}$ cocaine were an artifact of the switch in cocaine dose and reinforcement schedule, caused either by learning or doseinduced rate-limiting effects. Indeed, it has been reported that stability of responding on a PR schedule can take time to develop (Depoortere et al., 1993). However, given that rats exposed to five additional FR1 sessions at $1.2 \mathrm{mg} / \mathrm{kg} / \mathrm{infusion}$ cocaine before PR testing (group C) exhibited significantly greater rates of responding (i.e., break points) than the limited exposure group on the first session, these differences are not likely explained by the need to learn to respond at higher rates. Furthermore, in the Liu et al. (2005) study, rats were trained with $1.5 \mathrm{mg} / \mathrm{kg} / \mathrm{infusion}$ cocaine before PR testing with that same dose and still exhibited break points similar to those in our study on the first session. Thus, it also seems unlikely that the switch in cocaine dose produced competitive behaviors on the first session, preventing higher break points.

Rather, we believe the dose-dependent change in break points seen in the limited-exposure group reflects sensitization to the motivational effects of cocaine, similar to previous reports (Liu et al., 2005; Morgan et al., 2006). In addition, our results revealed a dose-dependent early escalation in cocaine consumption that occurs during 2-h FR1 sessions. Rats given limited initial exposure to a moderate dose of cocaine (0.6 $\mathrm{mg} / \mathrm{kg} /$ infusion) during acquisition and then switched to a higher dose (1.2 mg/kg/infusion) increased consumption $45 \%$ over five additional sessions (see Fig. 2A). Although at first this may be surprising given reports in the literature of well trained animals' ability to regulate intake when cocaine dose is varied (Pickens and Thompson, 1968; Gerber and Wise, 1989; Lynch et al., 1998; Panlilio et al., 2003), our animals received minimal training before the switch in cocaine dose. Furthermore, there are now many paradigms that model an escalation of consumption, and they all demonstrate conditions that produce instability of intake (i.e., escalation) (Carroll et al., 1989; Fitch and Roberts, 1993; Ahmed and Koob, 1998; Tornatzky and Miczek, 2000). Thus, we believe we have established an exciting new model of escalation in cocaine consumption that can be revealed under standard self-administration conditions (FR1 schedules, 2-h sessions, separate housing rooms, etc.).

It is tempting to conclude that the increase in consumption on the FR1 schedule is related to sensitization, as was revealed on the $\mathrm{PR}$ schedule, given the similar time course of the two effects (first five sessions at the higher dose; see Figs. $1 \mathrm{C}$ and 2A). In addition, rats that escalated consumption (group C) displayed significantly greater break points than rats in the limited-exposure group on the first PR session (Fig. 2C), possibly because some change in the motivational effects of cocaine had occurred as a result. However, until we are able to fully assess the reinforcing effectiveness of cocaine after this escalation on the FR schedule (e.g., with dose-consumption analysis), we are unable to know whether this truly is a sensitization effect revealed under the FR schedule.

Although we were able to identify conditions that produced sensitization to the motivational effects of cocaine, we did not observe differences between LCRs and HCRs in this form of sensitization. Thus, under conditions that produced sensitization, break points increased for both LCRs and HCRs. It should be noted that the relationship between locomotor sensitization and sensitization to the effects of self-administered cocaine is unclear. Although some studies have found that prior noncontingent stimulant exposure decreases latency to acquisition and increases break points for cocaine (Schenk and Partridge, 2000; Suto et al., 2002), other studies 
(including our own LCR/HCR study) have found that cocaineinduced locomotor sensitization does not predict acquisition or break points (Lack et al., 2008; Mandt et al., 2008) and is dissociable from the motivational effects after compulsive cocaine consumption (Ahmed and Cador, 2006). Furthermore, noncontingent cocaine administration, such as that used to induce locomotor sensitization, is known under some conditions to produce different neurobiological effects than contingent cocaine administration (Chen et al., 2008; Miguéns et al., 2008). Finally, the amount of cocaine exposure during self-administration far exceeds that of multiple intermittent injections, making direct comparison of these findings difficult.

The current study replicated previous findings on the important role of cocaine dose and exposure history for sensitization to the effects of self-administered cocaine. In addition, we extended these findings to show that this form of sensitization can be revealed under standard training conditions and occurs very early in the drug-taking process. Furthermore, we revealed conditions (switch from a moderate to a high dose of cocaine) that lead to an early escalation of cocaine consumption on a FR1 schedule of reinforcement during 2 -h sessions. Thus, this study provides important evidence that sensitization may be a process involved during the earliest stages of drug taking when experience is limited and may help explain the contribution of this phenomenon to the rapid progression of cocaine addiction in some people.

\section{Acknowledgments}

We thank Jillian Laggart, Kari Massar, Merissa Pickell, and Alyssa Schickedanz for their dedicated help with data collection.

\section{Authorship Contributions}

Participated in research design: Mandt, Gomez, Johnston, Zahniser, and Allen.

Conducted experiments: Mandt, Gomez, and Johnston.

Performed data analysis: Mandt and Allen.

Wrote or contributed to the writing of the manuscript: Mandt, Zahniser, and Allen.

\section{References}

Ahmed SH and Cador M (2006) Dissociation of psychomotor sensitization from compulsive cocaine consumption. Neuropsychopharmacology 31:563-571.

Ahmed SH and Koob GF (1998) Transition from moderate to excessive drug intake: change in hedonic set point. Science 282:298-300.

Allen RM, Everett CV, Nelson AM, Gulley JM, and Zahniser NR (2007) Low and high locomotor responsiveness to cocaine predicts intravenous cocaine conditioned place preference in male Sprague-Dawley rats. Pharmacol Biochem Behav 86:37-44.

Bradberry CW (2007) Cocaine sensitization and dopamine mediation of cue effects in rodents, monkeys, and humans: areas of agreement, disagreement, and implications for addiction. Psychopharmacology (Berl) 191:705-717.

Carroll ME and Lac ST (1997) Acquisition of i.v. amphetamine and cocaine selfadministration in rats as a function of dose. Psychopharmacology (Berl) 129:206214.

Carroll ME, Lac ST, and Nygaard SL (1989) A concurrently available nondrug reinforcer prevents the acquisition or decreases the maintenance of cocainereinforced behavior. Psychopharmacology (Berl) 97:23-29.

Chen BT, Bowers MS, Martin M, Hopf FW, Guillory AM, Carelli RM, Chou JK, and Bonci A (2008) Cocaine but not natural reward self-administration nor passive cocaine infusion produces persistent LTP in the VTA. Neuron 59:288297.

Churchill L, Swanson CJ, Urbina M, and Kalivas PW (1999) Repeated cocaine alters glutamate receptor subunit levels in the nucleus accumbens and ventral tegmental area of rats that develop behavioral sensitization. J Neurochem 72:2397-2403.

Depoortere RY, Li DH, Lane JD, and Emmett-Oglesby MW (1993) Parameters of self-administration of cocaine in rats under a progressive-ratio schedule. Pharmacol Biochem Behav 45:539-548.

Deroche-Gamonet V, Belin D, and Piazza PV (2004) Evidence for addiction-like behavior in the rat. Science 305:1014-1017.

Fitch TE and Roberts DC (1993) The effects of dose and access restrictions on the periodicity of cocaine self-administration in the rat. Drug Alcohol Depend 33:119 128.

Gawin FH (1991) Cocaine addiction: psychology and neurophysiology. Science 251: 1580-1586.

Gerber GJ and Wise RA (1989) Pharmacological regulation of intravenous cocaine and heroin self-administration in rats: a variable dose paradigm. Pharmacol Biochem Behav 32:527-531.

Grignaschi G, Burbassi S, Zennaro E, Bendotti C, and Cervo L (2004) A single high dose of cocaine induces behavioural sensitization and modifies mRNA encoding GluR1 and GAP-43 in rats. Eur J Neurosci 20:2833-2837.

Institute of Laboratory Animal Resources (1996) Guide for the Care and Use of Laboratory Animals 7th ed. Institute of Laboratory Animal Resources, Commission on Life Sciences, National Research Council, Washington, DC.

Kalivas PW and Duffy P (1993) Time course of extracellular dopamine and behavioral sensitization to cocaine. I. Dopamine axon terminals. J Neurosci 13:266-275.

Lack CM, Jones SR, and Roberts DC (2008) Increased breakpoints on a progressive ratio schedule reinforced by IV cocaine are associated with reduced locomotor activation and reduced dopamine efflux in nucleus accumbens shell in rats. Psychopharmacology (Berl) 195:517-525.

Lambert NM, McLeod M, and Schenk S (2006) Subjective responses to initial experience with cocaine: an exploration of the incentive-sensitization theory of drug abuse. Addiction 101:713-725

Liu Y, Roberts DC, and Morgan D (2005) Sensitization of the reinforcing effects of self-administered cocaine in rats: effects of dose and intravenous injection speed. Eur $J$ Neurosci 22:195-200.

Lynch WJ, LaBounty LP, and Carroll ME (1998) A novel paradigm to investigate regulation of drug intake in rats self-administering cocaine or heroin intravenously. Exp Clin Psychopharmacol 6:22-31.

Mandt BH, Allen RM, and Zahniser NR (2009) Individual differences in initial low-dose cocaine-induced locomotor activity and locomotor sensitization in adult outbred female Sprague-Dawley rats. Pharmacol Biochem Behav 91:511-516.

Mandt BH, Johnston NL, Zahniser NR, and Allen RM (2012) Acquisition of cocaine self-administration in male Sprague-Dawley rats: effects of cocaine dose but not initial locomotor response to cocaine. Psychopharmacology (Berl) 219:1089-1097.

Mandt BH, Schenk S, Zahniser NR, and Allen RM (2008) Individual differences in cocaine-induced locomotor activity in male Sprague-Dawley rats and their acquisition of and motivation to self-administer cocaine. Psychopharmacology (Berl) 201:195-202.

Mandt BH and Zahniser NR (2010) Low and high cocaine locomotor responding male Sprague-Dawley rats differ in rapid cocaine-induced regulation of striatal dopamine transporter function. Neuropharmacology 58:605-612.

Mantsch JR, Ho A, Schlussman SD, and Kreek MJ (2001) Predictable individual differences in the initiation of cocaine self-administration by rats under extended-access conditions are dose-dependent. Psychopharmacology (Berl) 157: 31-39.

Miguéns M, Crespo JA, Del Olmo N, Higuera-Matas A, Montoya GL, GarcíaLecumberri C, and Ambrosio E (2008) Differential cocaine-induced modulation of glutamate and dopamine transporters after contingent and non-contingent administration. Neuropharmacology 55:771-779.

Morgan D, Liu Y, and Roberts DC (2006) Rapid and persistent sensitization to the reinforcing effects of cocaine. Neuropsychopharmacology 31:121-128.

Morgan D and Roberts DC (2004) Sensitization to the reinforcing effects of cocaine following binge-abstinent self-administration. Neurosci Biobehav Rev 27:803-812.

Nelson AM, Larson GA, and Zahniser NR (2009) Low or high cocaine responding rats differ in striatal extracellular dopamine levels and dopamine transporter number. J Pharmacol Exp Ther 331:985-997.

O'Brien MS and Anthony JC (2005) Risk of becoming cocaine dependent: epidemiological estimates for the United States, 2000-2001. Neuropsychopharmacology 30:1006-1018

Panlilio LV, Katz JL, Pickens RW, and Schindler CW (2003) Variability of drug self-administration in rats. Psychopharmacology (Berl) 167:9-19.

Pickens R and Thompson T (1968) Cocaine-reinforced behavior in rats: effects of reinforcement magnitude and fixed-ratio size. J Pharmacol Exp Ther 161:122129

Post RM (1980) Intermittent versus continuous stimulation: effect of time interval on the development of sensitization or tolerance. Life Sci 26:1275-1282.

Richardson NR and Roberts DC (1996) Progressive ratio schedules in drug selfadministration studies in rats: a method to evaluate reinforcing efficacy. $J \mathrm{Neu}$ rosci Methods 66:1-11.

Rinaldi RC, Steindler EM, Wilford BB, and Goodwin D (1988) Clarification and standardization of substance abuse terminology. JAMA 259:555-557.

Robinson TE and Berridge KC (1993) The neural basis of drug craving: an incentivesensitization theory of addiction. Brain Res Brain Res Rev 18:247-291.

Robinson TE and Berridge KC (2001) Incentive-sensitization and addiction. Addiction 96:103-114

Sabeti J, Gerhardt GA, and Zahniser NR (2002) Acute cocaine differentially alters accumbens and striatal dopamine clearance in low and high cocaine locomotor responders: behavioral and electrochemical recordings in freely moving rats. $J$ Pharmacol Exp Ther 302:1201-1211.

Sabeti J, Gerhardt GA, and Zahniser NR (2003) Individual differences in cocaineinduced locomotor sensitization in low and high cocaine locomotor-responding rats are associated with differential inhibition of dopamine clearance in nucleus accumbens. J Pharmacol Exp Ther 305:180-190.

Schenk S and Partridge B (2000) Sensitization to cocaine's reinforcing effects produced by various cocaine pretreatment regimens in rats. Pharmacol Biochem Behav 66:765-770.

Shaham Y, Shalev U, Lu L, De Wit H, and Stewart J (2003) The reinstatement model of drug relapse: history, methodology and major findings. Psychopharmacology (Berl) 168:3-20.

Substance Abuse and Mental Health Services Administration (2011) Results from 
the 2010 National Survey on Drug Use and Health: Summary of National Findings, NSDUH Series H-41, HHS Publication SMA-11-4658. Substance Abuse and Mental Health Services Administration, Rockville, MD.

Suto N, Austin JD, Tanabe LM, Kramer MK, Wright DA, and Vezina P (2002) Previous exposure to VTA amphetamine enhances cocaine self-administration under a progressive ratio schedule in a D1 dopamine receptor dependent manner. Neuropsychopharmacology 27:970-979.

Thomsen M and Caine SB (2005) Chronic intravenous drug self-administration in rats and mice. Curr Protoc Neurosci Chapter 9:Unit 9.20.

Tornatzky W and Miczek KA (2000) Cocaine self-administration "binges": transition from behavioral and autonomic regulation toward homeostatic dysregulation in rats. Psychopharmacology (Berl) 148:289-298.
Wagner FA and Anthony JC (2002) From first drug use to drug dependence; developmental periods of risk for dependence upon marijuana, cocaine, and alcohol. Neuropsychopharmacology 26:479-488.

Zahniser NR, Peris J, Dwoskin LP, Curella P, Yasuda RP, O’Keefe L, and Boyson SJ (1988) Sensitization to cocaine in the nigrostriatal dopamine system. NIDA Res Monogr 88:55-77.

Address correspondence to: Bruce H. Mandt, Department of Psychology, University of Colorado Denver, P.O. Box 173364, Campus Box 173, Denver, CO 80217. E-mail: bruce.mandt@ucdenver.edu 